\title{
Perfusion/ventilation mismatch during exercise in chronic heart failure: an investigation of circulatory determinants
}

\author{
Adrian P Banning, Neil P Lewis, David B Northridge, J Stuart Elborn,
} Andrew $\mathrm{H}$ Henderson

\begin{abstract}
Background-The ventilatory cost of carbon dioxide $\left(\mathrm{CO}_{2}\right)$ elimination on exercise $\left(\mathrm{VE} / \mathrm{VCO}_{2}\right)$ is increased in chronic heart failure (CHF). This reflects increased physiological dead space ventilation secondary to mismatching between perfusion and ventilation during exercise. The objectives of this study were to investigate the relation of this increased $\mathrm{VE} / \mathrm{VCO}_{2}$ slope to the syndrome of CHF or to limitation of the exercise related increase of pulmonary blood flow, or both.
\end{abstract}

Patients and methods-Maximal treadmill exercise tests with respiratory gas analysis were performed in 45 patients with CHF (defined as resting left ventricular ejection fraction $<40 \%$ on radionuclide scan); 15 normal controls; 23 patients with coronary artery disease and normal resting left ventricular function; and 13 pacemaker dependent patients (six with and seven without CHF) directly comparing exercise responses in rate responsive and fixed rate mode.

Results-Patients with CHF had a steeper $\mathrm{VE} / \mathrm{VCO}_{2}$ slope than normal controls: this was related inversely to peak $\mathrm{VO}_{2}$ below $20 \mathrm{~mol} / \mathrm{min} / \mathrm{kg}$. In patients with coronary artery disease in whom peak $\mathrm{Vo}_{2}$ (at respiratory exchange ratio $>1$ ) was as limited as in the patients with CHF but resting left ventricular function was normal, the VE/ $/ \mathrm{CO}_{2}$ slope was normal. In pacemaker dependent patients fixed rate pacing resulted in lower exercise capacity and peak $\mathrm{Vo}_{2}$ than rate responsive pacing; the $\mathrm{VE} / \mathrm{VCO}_{2}$ slope was normal in patients without CHF but steeper than normal in patients with $\mathrm{CHF}$; the VE/VCo 2 slope was steeper during fixed rate than during rate responsive pacing in these patients with CHF.

Conclusions-These findings suggest that the perfusion/ventilation mismatch during exercise in CHF is related to the chronic consequences of the syndrome and not directly to limitation of exercise related pulmonary flow. Only when the syndrome of CHF is present can matching between perfusion and ventilation be acutely influenced by changes in pulmonary flow.

(Br Heart f 1995;74:27-33)

Keywords: chronic heart failure; perfusion and ventilation during exercise; carbon dioxide elimination
Ventilation is increased relative to workload in chronic heart failure (CHF). ${ }^{2}$ This is in part the result of increased production of carbon dioxide $\left(\mathrm{CO}_{2}\right)$ from bicarbonate buffering of the lactic acid produced by anaerobic metabolism of exercising skeletal muscle at a lower than normal workload. ${ }^{34}$ It also reflects a greater ventilatory cost of $\mathrm{CO}_{2}$ excretion during exercise as reflected in a steeper slope of the linear relation of minute ventilation to $\mathrm{CO}_{2}$ production $\left(\mathrm{VE} / \mathrm{VCO}_{2}\right)^{5-7}$ with maintenance of normal blood gas concentrations. ${ }^{2689}$ The increase in the steepness of the $\mathrm{VE} / \mathrm{VCO}_{2}$ slope reflects an increase in physiological dead space ventilation during exercise, attributable to mismatching between perfusion and ventilation. ${ }^{57}$ The slope is related to the severity of the functional limitation, being inversely related to exercise tolerance and peak $\mathrm{VO}_{2} .{ }^{59}$ It has been shown not to correlate with haemodynamic variables such as pulmonary capillary wedge pressure. ${ }^{2} 10$

CHF is associated with several factors that might influence pulmonary perfusion/ventilation matching. These include the direct consequences of a smaller increase in exercise cardiac output (and thus in total pulmonary flow during exercise) than in normal individuals and also non-cardiac poorly understood components of the syndrome of CHF (for example, vascular), reflecting the chronic compensatory response to impaired cardiac performance.

This study addresses the question is "exercise related perfusion/ventilation mismatch related directly to limitation of overall pulmonary flow during exercise or is it a chronic feature of the CHF syndrome?" In this study we chose to characterise $\mathrm{CHF}$ according to the presence of impaired resting left ventricular function, to represent the stimuli for the chronic compensatory responses of $\mathrm{CHF}$. We measured exercise responses in a group of patients with $\mathrm{CHF}$ and compared them with a group of normal controls. These largely confirmatory studies then provided the basis against which we carried out two further discriminatory studies. First, the $\mathrm{VE} / \mathrm{VCO}_{2}$ slope was measured in patients in whom exercise tolerance and peak $\mathrm{Vo}_{2}$ were limited by exercise induced myocardial ischaemia as in the patients with CHF, but in whom resting left ventricular function was normal. The respiratory exchange ratio $\left(\mathrm{VCO}_{2} / \mathrm{Vo}_{2}\right)$ at peak exercise in these patients was $>1$, indicative of limitation of skeletal muscle perfusion comparable to that in patients with $\mathrm{CHF}$, implying 
that exercise was similarly limited by cardiac output. Second, we investigated whether the $\mathrm{VE} / \mathrm{VCO}_{2}$ slope could be altered acutely by reducing the increase in exercise cardiac output and pulmonary flow, by studying pacemaker dependent patients in whom we were able to compare the exercise responses in fixed rate and rate responsive pacing modes.

\section{Patients and methods \\ PATIENT GROUPS}

Group 1 comprised 45 patients $(35$ men and 10 women of mean (SD) age 51 (11) years) with clinically stable chronic heart failure. Chronic heart failure is defined here as chronic impairment of resting left ventricular function as measured by radionuclide left ventricular ejection fraction $<40 \%$. Heart failure was of mixed aetiology: 36 patients (mean (SD) age 59 (9) years, of whom 25 were men) had ischaemic heart disease (IHD) but no angina and no electrocardiographic evidence of inducible myocardial ischaemia during exercise; nine patients (mean (SD) age 41 (11) years of whom eight were men) had dilated cardiomyopathy (DCM). Treatment, continued throughout the study, comprised frusemide (mean $60 \mathrm{mg}$ daily) in all patients, digoxin in 10, and angiotensin converting enzyme inhibitors in 13. Two patients were in New York Heart Association (NYHA) functional class I, 19 in class II, 18 in class III, and six in class IV. No patient had clinical or radiographic evidence of fluid retention, pulmonary oedema, or thromboembolic or bronchopulmonary disease.

In 15 of these 45 patients (mean (SD) age 47 (8) years, of whom 12 were men, 11 with IHD, and four with DCM), arterial blood was sampled through a brachial artery cannula, allowing calculation of the ratio of dead space to tidal volume $\left(\mathrm{V}_{\mathrm{d}} / \mathrm{V}_{\mathrm{t}}\right)$ from $\mathrm{PaCO}_{2}$ and mixed expired $\mathrm{CO}_{2}\left(\mathrm{PeCO}_{2}\right)$.

Group 2 comprised 15 normal individuals (mean (SD) age 43 (18) years, of whom eight were men) who were similarly studied.

Group 3 comprised 23 patients with coronary artery disease and exercise induced myocardial ischaemia, all of whom had normal resting left ventricular function (ejection fraction $>50 \%$ ). Treatment, discontinued $24 \mathrm{~h}$ before the test, consisted of a nitrovasodilator and a calcium antagonist in all patients, and a $\beta$ adrenoceptor antagonist in all but three. Data were analysed separately for (i) a subgroup of 12 patients (mean (SD) age 58 (7) years, of whom 10 were men) with a peak $\mathrm{Vo}_{2}<20 \mathrm{ml} / \mathrm{min} / \mathrm{kg}(13.7(3.9) \mathrm{ml} / \mathrm{min} /$ $\mathrm{kg}$ ) and (ii) a subgroup of 11 patients (mean (SD) age 58 (9) years, of whom nine were men) with a peak $\mathrm{Vo}_{2}>20 \mathrm{ml} / \mathrm{min} / \mathrm{kg}(24.6$ $(3 \cdot 2) \mathrm{ml} / \mathrm{min} / \mathrm{kg}$ ). In the first subgroup nine patients had significant three vessel disease and three significant two vessel disease; in the second subgroup six had three vessel disease, four two vessel disease, and one single vessel disease. The respiratory exchange ratio $\left(\mathrm{VCO}_{2} / \mathrm{VO}_{2}\right)$ was $>1$ at peak exercise in all patients.
Group 4 comprised 13 patients (mean (SD) age 66 (9) years, of whom nine were men) whose pacemakers had been implanted $>2$ years previously and who were maintained with rate responsive pacing (six with dual chamber pacemakers and seven with rate responsive ventricular pacemakers). Six 무 patients (mean (SD) age 68 (7) years, of $I$ whom five were men; three with dual chamber pacemakers and three with rate responsive $\frac{\overrightarrow{7}}{\mathrm{C}}$ ventricular pacemakers) had treated chronic heart failure of mixed aetiology (two IHD, three DCM, and one after total correction of $\bar{c}$ Fallot's tetralogy), defined and characterised 흠 as in group 1. Treatment, continued through- $\frac{D}{\vec{D}}$

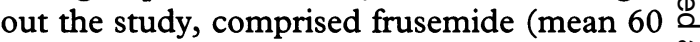
$\mathrm{mg}$ daily) in all patients and a calcium antago- के nist in one. A control group was provided by $\overrightarrow{0}$ seven patients (mean (SD) age 65 (3) years, of whom four were men; three with dual $\omega_{0}$ chamber pacemakers and four with rate responsive ventricular pacemakers) with no other known cardiovascular disease and normal resting left ventricular function (ejection $\overrightarrow{\mathrm{N}}$ fraction $>50 \%$ ).

PROTOCOL

All patients underwent maximal symptom $\stackrel{\complement}{=}$ limited treadmill exercise testing $>2 \mathrm{~h}$ after $\vec{\theta}$ food using either the Weber protocol ${ }^{11}$ of (groups 1, 2, and 4) or standard Bruce protocol (group 3). Blood pressure, heart rate, and 12 lead electrocardiogram were recorded at rest, the end of each 2 min stage of exercise, and peak exercise. Expired gases were sam- $\frac{D}{D}$ pled during exercise by a mass spectrometer $\overrightarrow{\vec{O}}$ using the argon dilution technique ${ }^{12}$ to give on $\frac{\circ}{3}$ line measurement of minute ventilation (VE), minute $\mathrm{CO}_{2}$ production $\left(\mathrm{VCO}_{2}\right)$ and minute oxygen consumption $\left(\mathrm{VO}_{2}\right)$, as previously reported. ${ }^{6}$ Respiratory rate (Fbr) was recorded over the final $30 \mathrm{~s}$ of each exercise stage. Peak $\mathrm{VO}_{2}$ was determined from the $\underline{3}$. mean $\mathrm{Vo}_{2}$ over the final $30 \mathrm{~s}$ of exercise. The 8 relation during exercise between $\mathrm{VE}$ and $\mathrm{VCO}_{2}$ was analysed by linear regression:

$$
\mathrm{VE}=m \mathrm{VCO}_{2}+c
$$

where $m$ is the slope of $\mathrm{VE} / \mathrm{VCO}_{2}$ and $c$ is the $\mathrm{VE}$ axis intercept). Figure 1 illustrates the lin- $\sigma$ ear $\mathrm{VE} / \mathrm{VCO}_{2}$ response recorded in real time $\tilde{O}$ during exercise, this relation being linear in $\underset{\omega}{N}$ every patient $(r>0.92$ in every case).

In a representative subgroup of patients 0 with chronic heart failure, ethical approval $\mathbb{D}$ was obtained for arterial blood to be sampled via a brachial artery cannula for measurement $\frac{0}{0}$ of $\mathrm{pH}$, arterial oxygen pressure $\left(\mathrm{PaO}_{2}\right)$, arterial $\underset{\mathbb{D}}{\stackrel{0}{*}}$ carbon dioxide pressure $\left(\mathrm{Pa} \mathrm{Co}_{2}\right)$, and bicar- $\frac{\rho}{\mathrm{D}}$ bonate and lactate concentrations. Physio- $\varrho$ logical dead space (VD) was calculated from $\mathrm{PaCO}_{2}$, mixed expired $\mathrm{CO}_{2}\left(\mathrm{PeCO}_{2}\right)$ and tidal 8 volume (VT), after correcting for equipment dead space, according to the Bohr equation:

$$
\mathrm{VD}=\frac{\mathrm{PaCo}_{2}-\mathrm{PeCO}_{2}}{\mathrm{PaCo}_{2}} \cdot \mathrm{VT}
$$

The physiological dead space was then expressed in relation to tidal volume $(\mathrm{VD} / \mathrm{VT}) \mathrm{r}^{13}$ 
Table 1 Haemodynamic and respiratory data during treadmill exercise in patients with chronic heart failure (CHF) and in normal controls

\begin{tabular}{lll}
\hline & Patients with $\mathrm{CHF}(n=45)$ & Normal controls $(n=15)$ \\
\hline Exercise duration $(\mathrm{min})$ & $11 \cdot 4(6 \cdot 6)^{\star}$ & $23 \cdot 7(6 \cdot 1)$ \\
Peak $\mathrm{VO}_{2}(\mathrm{ml} / \mathrm{min} / \mathrm{kg})$ & $16 \cdot 7(7 \cdot 2)^{\star}$ & $29 \cdot 7(7 \cdot 2)$ \\
$\mathrm{RERmax}\left(\mathrm{VCO}_{2} / \mathrm{VO}_{2}\right)$ & $1 \cdot 12(0 \cdot 15)$ & $1 \cdot 20(0 \cdot 12)$ \\
$\mathrm{VE} / \mathrm{VCO}_{2}$ & & \\
$m$ & $38(13)^{\star}$ & $26(5)$ \\
$c(1 / \mathrm{min})$ & $3 \cdot 2(2 \cdot 9)$ & $2 \cdot 6(2 \cdot 2)$ \\
$r$ & $0.98(0 \cdot 01)$ & $0.99(0.01)$
\end{tabular}

Values are mean (SD). ${ }^{\star} \mathrm{P}<0.05 v$ normal controls (Student's $t$ test). Peak $\mathrm{VO}_{2}$, oxygen consumption at peak exercise, RERmax, respiratory exchange ratio at peak exercise; $\mathrm{VCO}_{2}$, minute carbon dioxide production; $\mathrm{VE} / \mathrm{VCO}_{2}$, minute ventilation/minute carbon dioxide production; $m$ slope of $\mathrm{VE} / \mathrm{VCO}_{2} ; c$, intercept; $r$, linear regression correlation coefficient.

Pacemaker dependent patients, normally maintained in rate responsive mode, performed two exercise tests in random order (single blind) with $30 \mathrm{~min}$ recovery between tests: (i) rate responsive ventricular pacing or dual chamber (resting demand rate 70 beats $/ \mathrm{min}$ ) and (ii) fixed rate ventricular pacing (resting demand rate 50 beats $/ \mathrm{min}$ ).

\section{INFORMED CONSENT}

The study protocols were approved by the Ethical Committee of the University Hospital of Wales and informed consent was obtained in each case.

\section{STATISTICAL ANALYSIS}

Data are reported as group mean (SD). The significance of differences between groups was tested using Student's $t$ test for paired or unpaired data as appropriate. $P<0.05$ was considered significant.

\section{Results}

EXERCISE VENTILATION RESPONSE IN PATIENTS WITH CHRONIC HEART FAILURE AND IN NORMAL INDIVIDUALS

The VE/ $/ \mathrm{VO}_{2}$ slope was significantly steeper in patients with heart failure (group 1) than in normal individuals (group 2). Table 1 shows no significant difference in the correlation coefficient between the two groups or in the intercept $(c)$ of the relation. The respiratory exchange ratio $\left(\mathrm{VCO}_{2} / \mathrm{No}_{2}\right)$ at peak symptom limited exercise (RERmax) was $>1$ in all participants of both groups, demonstrating that

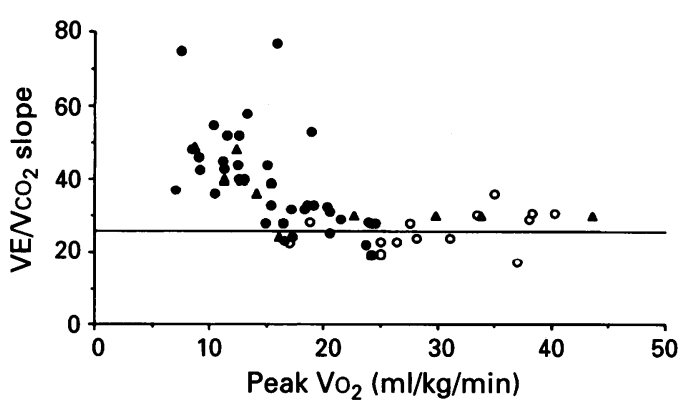

Figure 2 Minute ventilation/minute carbon dioxide production $\left(\mathrm{VE} / \mathrm{VCO}_{2}\right)$ slope plotted as function of maximal oxygen consumption (peak $\mathrm{VO}_{2}$ ) in normal controls (O) and patients with ischaemic heart disease (O) or dilated cardiomyopathy (A). The solid line represents the group mean (SD) (26 (5)) for controls. Note that the inverse relation between the $\mathrm{VE} / \mathrm{VCO} \mathrm{O}_{2}$ slope and peak $\mathrm{VO}_{2}$ below peak $\mathrm{VO}_{2}$ about $20 \mathrm{ml} / \mathrm{min} / \mathrm{kg}$ in chronic heart failure is independent of aetiology.

exercise was near to the physiological maximum. Figure 1 shows representative examples of the linear $\mathrm{VE} / \mathrm{VCO}_{2}$ relation during exercise in a patient with chronic heart failure and in a normal control. The $\mathrm{VE} / \mathrm{VCO}_{2}$ slope was inversely related to peak $\mathrm{VO}_{2}$ in patients whose peak $\mathrm{VO}_{2}$ was $<20 \mathrm{ml} / \mathrm{min} / \mathrm{kg}(r=-0.87$ ) (fig 2). Figure 2 also shows that the relation seems to be independent of the aetiology of heart failure.

Table 2 gives data of the 15 patients with chronic heart failure in whom arterial blood gases were monitored during exercise. Arterial $\mathrm{PaCO}_{2}$ remained constant, raised lactate levels were not associated with any change in $\mathrm{pH}$ on exercise, and $\mathrm{PaO}_{2}$ increased slightly. The $\mathrm{VE} / \mathrm{VCO}_{2}$ slope correlated with $\mathrm{VD} / \mathrm{VT}$ measured at maximal exercise $(r=0 \cdot 86)$ (fig 3$)$.

\section{PATIENTS WITH CORONARY ARTERY DISEASE AND NORMAL RESTING LEFT VENTRICULAR FUNCTION}

Figure 4 shows that the $\mathrm{VE} / \mathrm{VCO}_{2}$ slope in patients with coronary artery disease and normal resting left ventricular function (group 3) remained normal and independent of peak $\mathrm{Vo}_{2}$, in contrast to patients with chronic heart failure (group 1) in whom the $\mathrm{VE} / \mathrm{VCO}_{2}$ slope was increased at peak $\mathrm{Vo}_{2}$ below about 20 $\mathrm{ml} / \mathrm{min} / \mathrm{kg}$. This was confirmed by separate

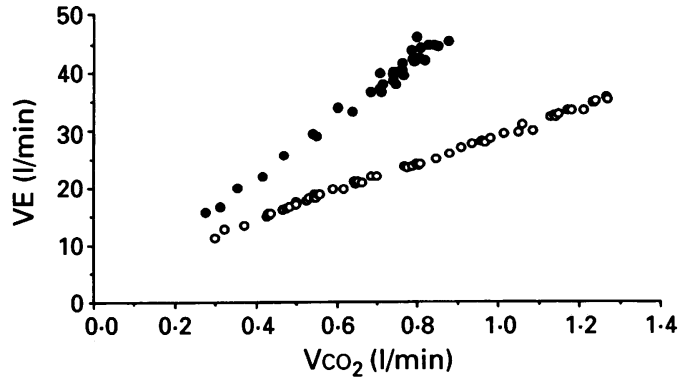

Figure 1 Representative examples showing a steeper minute ventilation/minute carbon dioxide production $\left(\mathrm{VE} / \mathrm{VCO}_{2}\right)$ linear relation in a patient with chronic heart failure (O) than in a normal control (O).
Table 2 Arterial blood gas and respiratory data from 15 patients with chronic heart failure during treadmill exercise

\begin{tabular}{|c|c|c|}
\hline & Rest & Maximum exercise \\
\hline Peak $\mathrm{VO}_{2}(\mathrm{ml} / \mathrm{min} / \mathrm{kg})$ & 一 & $15 \cdot 6(4 \cdot 1)$ \\
\hline RER $\max ^{\star}$ & - & $1.13(0.09)$ \\
\hline $\mathrm{VE} / \mathrm{VCO}_{2}$ slope & - & $39(6)$ \\
\hline $\mathrm{PaO}_{2}(\mathrm{~mm} \mathrm{Hg})$ & $97(11)$ & $108(14)^{\star}$ \\
\hline $\mathrm{PaCO}_{2}(\mathrm{~mm} \mathrm{Hg})$ & $38(6)$ & $36(6)$ \\
\hline & $7.42(0.04)$ & $7 \cdot 42(0.06)$ \\
\hline Lactate $(\mathrm{mmol} / \mathrm{l})$ & $0.9(0.3)$ & $3.9(1.0)^{\star}$ \\
\hline Bicarbonate $(\mathrm{mmol} / \mathrm{l})$ & $26 \cdot 0(4 \cdot 5)$ & $21 \cdot 7(5 \cdot 1)^{\star}$ \\
\hline $\mathrm{VE}(1 / \mathrm{min})$ & $13 \cdot 1(4 \cdot 0)$ & $47 \cdot 2(10 \cdot 2)^{\star}$ \\
\hline $\mathrm{Fbr}($ per min $)$ & $17(4)$ & $37(12)^{\star}$ \\
\hline VT (l) & $0.76(0.15)$ & $1.27(0.30)^{\star}$ \\
\hline $\mathrm{VD} / \mathrm{VT}$ & $0.57(0.11)$ & $0.42(0.14)^{\star}$ \\
\hline
\end{tabular}

Values are mean (SD). ${ }^{\star} \mathrm{P}<0.05 v$ rest (paired $t$ test). $\mathrm{PaO}_{2}$, arterial oxygen pressure; $\mathrm{PaCO}_{2}$, arterial carbon dioxide pressure; $\mathrm{Fbr}$ respiratory rate; $\mathrm{VT}$, tol volume; VD, physiological dead space; other abbreviations as given in table 1 . 
Figure 3 Minute ventilation/minute carbon dioxide production (VE/VCO $)$ slope, plotted as a function of $V D / V T$ at maximal exercise $\left(V_{D} / V_{T}\right.$ max) in 15 patients with chronic heart failure

(inear regression $r=0 \cdot 86$, $P<0.001$ ).

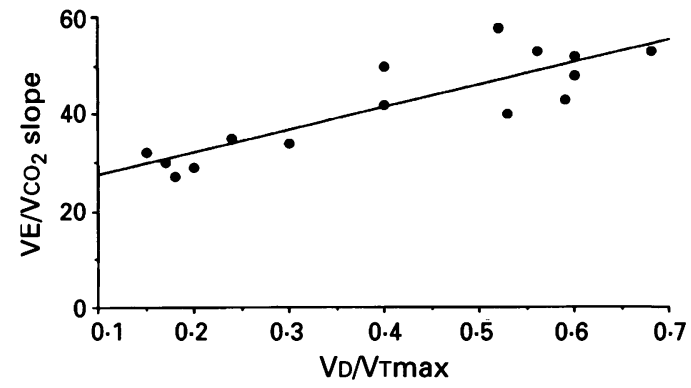

Figure 4 Minute ventilation/minute carbon dioxide production $\left(\mathrm{VE} / \mathrm{VCO}_{2}\right)$ slope plotted as function of maximal oxygen consumption (peak $V O_{2}$ ) in patients with coronary artery disease and normal resting left ventricular function. Note the lack of an inverse relation between the

$V E / V \mathrm{CO}_{2}$ slope and peak

$\mathrm{VO}_{2}$ in contrast to that of patients with chronic heart failure (in fig 2).

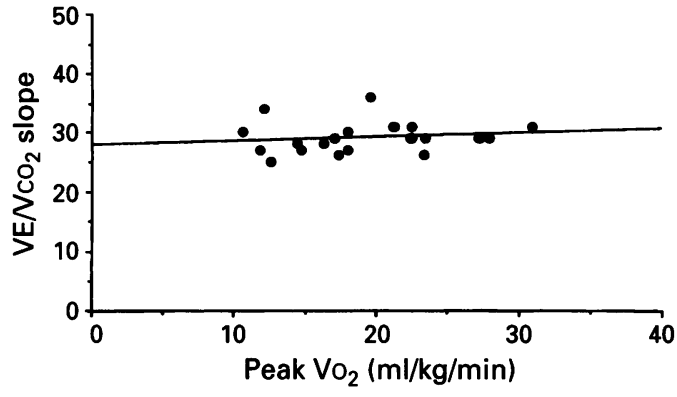

Table 3 Exercise responses in patients with normal resting $L V$ function but exercise induced myocardial ischaemia and RERmax $>1 \cdot 0$

\begin{tabular}{|c|c|c|}
\hline & $\begin{array}{l}\text { Peak VO} O_{2}<20 \mathrm{ml} / \mathrm{min} / \mathrm{kg} \\
(n=12)\end{array}$ & $\begin{array}{l}\text { Peak } \mathrm{VO}_{2}>20 \mathrm{ml} / \mathrm{min} / \mathrm{kg} \\
(n=11)\end{array}$ \\
\hline $\begin{array}{l}\text { Exercise duration (min) } \\
\text { Peak Vo }(\mathrm{ml} / \mathrm{min} / \mathrm{kg}) \\
\mathrm{RERmax}\left(\mathrm{VCO}_{2} / \mathrm{VO}_{2}\right)\end{array}$ & $\begin{array}{c}8.7(1 \cdot 6) \\
13.7(3.9)^{\star} \\
1.01(0.01)\end{array}$ & $\begin{array}{l}10 \cdot 2(2 \cdot 1) \\
24 \cdot 6(3 \cdot 2) \\
1 \cdot 11(0 \cdot 06)\end{array}$ \\
\hline $\begin{array}{l}\mathrm{VE} / \mathrm{VCO}_{2} \\
c(1 / \mathrm{min}) \\
r\end{array}$ & $\begin{array}{l}29(4) \\
2.8(1.3) \\
0.97(0.03)\end{array}$ & $\begin{array}{l}29(2) \\
3.1(1.11) \\
0.97(0.03)\end{array}$ \\
\hline
\end{tabular}

Values are mean (SD). ${ }^{\star} \mathrm{P}<0.05 v$ patients with peak $\mathrm{VO}_{2}>20 \mathrm{ml} / \mathrm{min} / \mathrm{kg}$ (Student's $t$ test). Abbreviations as given in table 1 .
EFFECT OF ACUTE CHANGE IN CHRONOTROPIC RESPONSE TO EXERCISE IN PACEMAKER DEPENDENT PATIENTS

The pacemaker dependent patients with $\mathrm{CHF}$ (group 4) had a lower exercise duration and peak $\mathrm{VO}_{2}$, in both pacing modes, than those with normal resting left ventricular function (table 4). They were also characterised by a steeper $\mathrm{VE} / \mathrm{VCO}_{2}$ slope, in each pacing mode, than those without CHF. Figure 5 shows that the data points relating $\mathrm{VE} / \mathrm{VCO}_{2}$ slope to peak $\mathrm{Vo}_{2}$ in the pacemaker dependent patients with and without CHF (group 4) fell within the same distribution as those of the non-paced patients with $\mathrm{CHF}$ (group 1) illustrated in fig 2 . The respiratory exchange ratio at peak exercise was $>1$ in all tests.

Fixed rate pacing, with loss of the $\vec{\circ}$ chronotropic response to exercise, led to a significantly lower exercise duration and peak $\mathrm{Vo}_{2}$ than rate responsive pacing in patients with and without $\mathrm{CHF}$ (table 4). In patients with $\mathrm{CHF}$, fixed rate pacing was also associated with a significantly steeper $\mathrm{VE} / \mathrm{VCO}_{2}$ slope than rate responsive pacing. In patients with normal resting left ventricular ejection fraction, the $\mathrm{VE} / \mathrm{VCO}_{2}$ slope was similar in the two pacing modes. Thus, where by inference the cardiac output response to exercise was limited by $\mathrm{CHF}$, the $\mathrm{VE} / \mathrm{VCO}_{2}$ slope was steeper than normal (as in the non-paced patients) and it could then be increased further by switching pacing modes to reduce acutely the cardiac output response to exercise.

Table 5 demonstrates that the greater exercise related ventilation in patients with $\mathrm{CHF}$ and fixed compared with rate responsive pacing was associated with no difference in tidal volume, indicating no change in the relative contribution of anatomical dead space to the total dead space ventilation.

analysis of patients with peak $\mathrm{Vo}_{2}<20$ $\mathrm{ml} / \mathrm{min} / \mathrm{kg}$ (table 3). Peak $\mathrm{Vo}_{2}$ for this patient subgroup was similar to that in patients with CHF (group 1) (13.7 (3.9) $v 16.7 \quad(7.2)$ $\mathrm{ml} / \mathrm{min} / \mathrm{kg}$ ). The respiratory exchange ratio at peak exercise was also $>1$ in all patients, indicating near maximal exercise capacity independent of the limiting symptom. The $\mathrm{VE} / \mathrm{NCO}_{2}$ slope was not increased, however, as it was in the patients with heart failure (group 1 ), but was similar to that in normal controls (group 2).

\section{Discussion}

This study confirms the increased ventilatory cost of $\mathrm{CO}_{2}$ elimination in patients with $\mathrm{CHF}$ (group 1) relative to normal controls (group 2). ${ }^{7}$ It confirms that the $\mathrm{VE} / \mathrm{VCO}_{2}$ relation is linear throughout exercise, ${ }^{25}$ and that its slope is inversely related to peak $\mathrm{VO}_{2}$ below a threshold of about $20 \mathrm{ml} / \mathrm{min} / \mathrm{kg}$. ${ }^{7}$ It shows also that this is independent of the aetiology of heart failure, a syndrome defined here by reference to resting left ventricular function.

Table 4 Effects of rate responsive and fixed rate pacing on exercise responses in pacemaker dependent patients with and without chronic heart failure (CHF)

\begin{tabular}{|c|c|c|c|c|}
\hline & \multicolumn{2}{|c|}{ Patients with $\mathrm{CHF}(n=6)$} & \multicolumn{2}{|c|}{ Patiets without CHF $(n=7)$} \\
\hline & $\begin{array}{l}\text { Pacing mode } \\
\text { Rate responsive }\end{array}$ & Fixed rate & $\begin{array}{l}\text { Pacing mode } \\
\text { Rate responsive }\end{array}$ & Fixed rate \\
\hline $\begin{array}{l}\text { Exercise duration (min) } \\
\text { Peak } \mathrm{Vo}_{2}(\mathrm{ml} / \mathrm{min} / \mathrm{kg}) \\
\mathrm{RERmax}\left(\mathrm{Vco}_{2} / \mathrm{Vo}_{2}\right) \\
\text { Heart rate increment (per min) }\end{array}$ & $\begin{array}{l}10 \cdot 8(3 \cdot 7) \dagger \\
16 \cdot 1(3 \cdot 4) \dagger \\
1.07(0.03) \\
49(5)\end{array}$ & $\begin{array}{r}8 \cdot 9(3 \cdot 1)^{\star} t \\
13 \cdot 1(2 \cdot 3)^{\star} t \\
1 \cdot 08(0 \cdot 06) \\
-\end{array}$ & $\begin{array}{l}15 \cdot 1(3 \cdot 1) \\
20 \cdot 1(1 \cdot 5) \\
1 \cdot 04(0 \cdot 02) \\
53(9)\end{array}$ & $\begin{array}{l}12 \cdot 1(3.3)^{\star} \\
16.9(0.9)^{\star} \\
1.05(0.04) \\
-\end{array}$ \\
\hline $\begin{array}{l}m \\
r(1 / \mathrm{min}) \\
r\end{array}$ & $\begin{array}{l}39(5) \dagger \\
3.8(1.5) \\
0.98(0.02)\end{array}$ & $\begin{array}{l}51(7)^{\star} \dagger \\
3.2(1.8) \\
0.98(0.03)\end{array}$ & $\begin{array}{l}31(2) \\
3.8(1.6) \\
0.97(0.02)\end{array}$ & $\begin{array}{l}32(1) \\
4.2(0.5) \\
0.98(0.03)\end{array}$ \\
\hline
\end{tabular}

Values are mean (SD). ${ }^{\star} \mathrm{P}<0.05 v$ rate responsive pacing; $\nmid \mathrm{P}<0.05 v$ respective control (Student's $t$ test). Abbreviations as given in table 1 . 


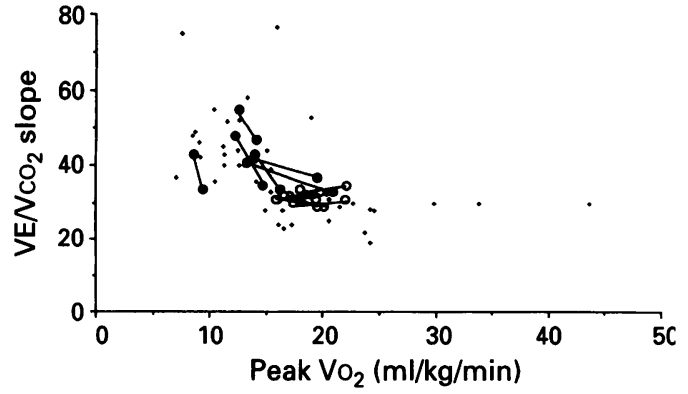

Figure 5 Minute ventilation/minute carbon dioxide production $\left(\mathrm{VE} / \mathrm{VCO}_{2}\right)$ slope plotted against maximal oxygen consumption (peak $\mathrm{VO}_{2}$ ) in pacemaker dependent patients, each pair of joined symbols representing fixed rate and rate responsive pacing mode in that patient. $O$ patients with normal resting left ventricular function; patients with impairment of resting left ventricular function; +, patients with CHF (group 1) reproduced from fig 2. Data from pacemaker dependent patients fall within the range represented by patients with heart failure and normal controls. Note that pacing induced reduction in peak $\mathrm{VO}_{2}$ is associated with an increase in the $\mathrm{VE} / \mathrm{VCO}_{2}$ slope in patients with CHF but not in those with normal resting left ventricular function.

The data also show that the VD/VT ratio at peak exercise is high in patients with CHF, as previously reported, ${ }^{25}$ and that it correlates with the $\mathrm{VE} / \mathrm{VCO}_{2}$ slope. Arterial $\mathrm{PaCO}_{2}$ and $\mathrm{pH}$ remained normal and $\mathrm{PaO}_{2}$ increased during exercise, as previously reported, ${ }^{2689}$ excluding an abnormality in gas transfer or alveolar hypoventilation. The findings therefore reflect an increase in dead space ventilation (VD). Dead space comprises equipment dead space (constant), anatomical dead space (unaltered if tidal volume is unchanged) or physiological dead space (calculated from the Bohr equation and indicative of relative underperfusion of ventilated alveoli). The increased $\mathrm{VE} / \mathrm{VCO}_{2}$ slope thus reflects mismatching between perfusion and ventilation during exercise.

The next part of the study addressed the question of whether or not an abnormally steep $\mathrm{VE} / \mathrm{VCO}_{2}$ slope is due to limitation of pulmonary flow with exercise (as is a feature of treated CHF) or whether it is caused by some other feature characterising the syn- drome of CHF. This question was addressed by studying patients with coronary heart disease (group 3) in whom exercise tolerance and peak $\mathrm{VO}_{2}$ were limited (at respiratory exchange ratio $>1.0$ ) by exercise induced ischaemia and myocardial dysfunction to a level comparable with that in patients with CHF (group 1), but resting left ventricular function was normal. In contrast to those with heart failure, the $\mathrm{VE} / \mathrm{VCO}_{2}$ slope in patients with coronary artery disease was normal and, moreover, it showed no relation to peak $\mathrm{Vo}_{2}$

This suggests that perfusion/ventilation mismatch during exercise depends on the presence of the chronic heart failure syndrome and is not caused exclusively by limitation of cardiac output and pulmonary flow during exercise. As cardiac output was not measured during exercise, this conclusion rests on the indirect evidence that exercise tolerance and peak $\mathrm{Vo}_{2}$ were both reduced to the same extent as in $\mathrm{CHF}$, and at a respiratory exchange ratio $\left(\mathrm{VCO}_{2} / \mathrm{Vo}_{2}\right)$ of $>1.0$ in each case, indicating anaerobiosis due to limitation of skeletal muscle perfusion. It could be argued that skeletal muscle perfusion does not bear the same relation to cardiac output in patients with $\mathrm{CHF}$ as it does in those without it. Evidence of altered skeletal muscle function and peripheral vascular behaviour in chronic heart failure ${ }^{14-16}$ would suggest, however, that skeletal muscle perfusion would not become limiting at a lower cardiac output in heart failure than in its absence. Cardiac output in patients with coronary artery disease (group 3) would therefore seem not to be overestimated relative to peak $\mathrm{Vo}_{2}$. Moreover, the fact that the $\mathrm{VE} / \mathrm{VCO}_{2}$ relation is linear and steeper throughout exercise suggests the presence of an underlying abnormality rather than simply a limitation of cardiac output and pulmonary flow which might appear only towards the limit of exercise tolerance.

The study then questioned whether the $\mathrm{VE} / \mathrm{VCO}_{2}$ slope can be altered by interventions which acutely alter the cardiac output response to exercise and thus the overall increase in pulmonary flow. Ethical and logistic considerations precluded direct

Table 5 Minute ventilation (VE), tidal volume (VT), and breathing frequency (Fbr) in pacemaker dependent patients with and without chronic heart failure (CHF) at rest, 6 min exercise (a workload achieved by all patients) and peak exercise

\begin{tabular}{|c|c|c|c|c|}
\hline & \multicolumn{2}{|c|}{$\begin{array}{l}\text { Patients with } C H F \\
(n=6)\end{array}$} & \multicolumn{2}{|c|}{$\begin{array}{l}\text { Patiets without } C H F \\
(n=7)\end{array}$} \\
\hline & $\begin{array}{l}\text { Pacing mode } \\
\text { Rate responsive }\end{array}$ & Fixed rate & $\begin{array}{l}\text { Pacing mode } \\
\text { Rate responsive }\end{array}$ & Fixed rate \\
\hline \multicolumn{5}{|l|}{$\mathrm{VE}(1 / \min )$} \\
\hline $\begin{array}{l}\text { Rest } \\
6 \text { min } \\
\text { Peak }\end{array}$ & $\begin{array}{l}13 \cdot 2(1 \cdot 7) \\
28 \cdot 4(4 \cdot 1) \\
51 \cdot 3(6 \cdot 7)\end{array}$ & $\begin{array}{l}14 \cdot 8(3 \cdot 4) \\
35 \cdot 3(5 \cdot 0)^{\star} \\
56 \cdot 1(7 \cdot 5)\end{array}$ & $\begin{array}{l}11 \cdot 2(2 \cdot 1) \\
23 \cdot 3(6 \cdot 3) \\
49 \cdot 4(8 \cdot 0)\end{array}$ & $\begin{array}{l}11 \cdot 9(1 \cdot 8) \\
24 \cdot 4(6 \cdot 5) \\
44.6(6 \cdot 1)\end{array}$ \\
\hline \multicolumn{5}{|l|}{$\mathrm{VT}(\mathrm{ml})$} \\
\hline $\begin{array}{l}\text { Rest } \\
6 \text { min } \\
\text { Peak }\end{array}$ & $\begin{array}{r}680(100) \\
870(130) \\
1200(190)\end{array}$ & $\begin{array}{c}710(94) \\
840(120) \\
1190(190)\end{array}$ & $\begin{array}{c}603(98) \\
830(170) \\
1250(190)\end{array}$ & $\begin{array}{c}621(74) \\
850(156) \\
1270(200)\end{array}$ \\
\hline \multicolumn{5}{|l|}{ Fbr (breath/min) } \\
\hline $\begin{array}{l}\text { Rest } \\
6 \text { min } \\
\text { Peak }\end{array}$ & $\begin{array}{l}20(2) \\
32(5) \\
42(6)\end{array}$ & $\begin{array}{l}20(4) \\
42(6)^{\star} \\
47(5)\end{array}$ & $\begin{array}{l}17(3) \\
26(5) \\
38(8)\end{array}$ & $\begin{array}{l}18(3) \\
27(8) \\
36(6)\end{array}$ \\
\hline
\end{tabular}

Values are mean $(\mathrm{SD}) .{ }^{\star} \mathrm{P}<0.05 v$ rate responsive pacing (paired $t$ test). 
measurement of cardiac output. We therefore took advantage of the fact that the exercise related increase in cardiac output is largely dependent on the heart rate response, ${ }^{17}$ and that this can be acutely altered in pacemaker dependent patients by switching from rate responsive to fixed rate pacing mode. We confirmed that these patients all demonstrated a lower maximum exercise duration and peak $\mathrm{VO}_{2}$ in fixed rate relative to rate responsive mode. Respiratory exchange ratio at peak exercise was $>1$ in all cases, indicating limitation of skeletal muscle perfusion and, by implication, of cardiac output (and thus total pulmonary flow) during exercise. In those pacemaker dependent patients who also had $\mathrm{CHF}$ with peak $\mathrm{Vo}_{2}<20 \mathrm{ml} / \mathrm{min} / \mathrm{kg}$, the $\mathrm{VE} / \mathrm{VCO}_{2}$ was increased as in other patients with CHF (group 1). Where it was already steeper than normal in these pacemaker dependent patients with CHF, it could be increased further by as much as $30 \%$ if the increase in cardiac output with exercise was limited by fixed rate instead of rate responsive pacing. In those pacemaker dependent patients with normal resting left ventricular ejection fraction, however, the $\mathrm{VE} / \mathrm{VCO}_{2}$ slope was normal; it remained normal, independent of pacing mode, despite a comparable reduction in exercise cardiac output with fixed rate relative to rate responsive pacing, as reflected in exercise duration and peak $\mathrm{Vo}_{2}$

Tani and colleagues ${ }^{18}$ have reported previously that fixed rate pacing relative to rate responsive pacing reduced exercise tolerance and peak $\mathrm{VO}_{2}$ and increased the $\mathrm{VE} / \mathrm{VCO}_{2}$ ratio (measured either at peak exercise or $1 \mathrm{~min}$ before the "anaerobic threshold"). In contrast to the present study which shows an increase in the $\mathrm{VE} / \mathrm{VCO}_{2}$ slope only in patients with chronic heart failure, the 10 patients in their study had echocardiographically normal left ventricular function. The reasons for this difference are not apparent; five of their patients were studied within 20 days of pacemaker implantation so that abnormalities associated with prior chronic heart failure may have persisted, but the findings seemed to be consistent in all their patients.

The findings of this study, considered together, suggest that the steep $\mathrm{VE} / \mathrm{VCO}_{2}$ slope reflects some feature of the chronic compensatory response to the CHF syndrome. Pulmonary microvascular dysfunction is an obvious contender to account, at least in part, for mismatching between perfusion and ventilation mismatch during exercise. The mechanisms underlying the control of microvascular perfusion in any vascular bed are complex. In addition to neurohumoral, metabolic, and chemical influences, and to intrinsic myogenic constriction which may be responsible for autoregulation of flow at different pressure gradients, flow related vasodilatation mediated by endothelium derived relaxant factor (EDRF) is an important integrating influence. ${ }^{1920}$ Experiments with intact systemic vascular beds indicate that flow related EDRF activity coordinates vasomotor behaviour and maintains homogeneity of flow distribution when driven at different flow rates: when EDRF activity was blocked, the microvascular distribution of perfusion no longer remained constant at different flow rates. ${ }^{21}$ Abnormalities of systemic microvascular function in chronic heart failure are well recognised. ${ }^{22-24}$ Moreover, recent evidence suggests that w EDRF activity is impaired in CHF ${ }^{25-27}$ There is, in addition, preliminary evidence that EDRF activity is also impaired in the pulmonary arteries in CHF. ${ }^{26}$ The mechanisms underlying these vascular features of chronic heart failure are poorly understood. They do not seem to be associated with fluid retention or haemodynamic factors and are likely to be a consequence of the neurohumoral changes which characterise the syndrome of $\mathrm{CHF}$, and of which are activated in response to any condi- $\vec{\circ}$ tion which prejudices the adequacy of cardiac output.

Dysfunction of pulmonary resistance arteries in chronic heart failure-which may be neurohumorally mediated and which may involve endothelial dysfunction-might thus account for loss of normal homoeodynamic control when overall flow of the pulmonary bed is increased as during exercise. This could interfere with the normal processes of matching perfusion to ventilation. Restoring homogeneity of pulmonary perfusion relative to ventilation might then provide a novel therapeutic approach to the management of exertional dyspnoea in patients with chronic heart failure.

AHH holds the British Heart Foundation Sir Thomas Lewis Chair of Cardiology. APB is a British Heart Foundation Junior Research Fellow. We thank Miss W Simons for secretarial assistance.

1 Weber KT, Kinasewitz GT, Janicki JS, Fishman AP. Oxygen utilization and ventilation during exercise in patients with chronic cardiac failure. Circulation 1982; 65:1213-23.

2 Sullivan MJ, Higginbotham MB, Cobb FR. Increased exercise ventilation in patients with chronic heart failure: intact ventilatory control despite haemodynamic and pulmonary abnormalities. Circulation 1988;77: and $\mathrm{p}$.

3 Weber KT, Janicki JS. Lactate production during maxima and submaximal exercise in patients with chronic heart failure. $\mathcal{F} \mathrm{Am}$ Coll Cardiol 1985;6:717-24.

4 Wilson JR, Mancini DM, Ferraro N, Egler J. Effect of dichloroacetate on the exercise performance of patients with heart failure. $\mathcal{A} \mathrm{Am}$ Coll Cardiol 1988;12:1464-9.

5 Buller NP, Poole-Wilson PA. Mechanism of the increased ventilatory response to exercise in patients with chronic heart failure. Br Heart $\mathcal{f} 1990 ; 63: 281-3$.

6 Lewis NP, Macdougall IC, Willis N, Henderson AH. The ventilatory cost of exercise compared in chronic heart failure and chronic renal anaemia. $Q \mathcal{F}$ Med 1992; 84:523-31. chronic renal anaemia. $Q f$ Med 1992; 84:523-31

Davies SW, Emery TM, Watling MIL, Wannamethee G, Lipkin DP. A critical threshold of exercise capacity in the ventilatory response to exercise in heart failure. $\mathrm{Br}$ Heart $\mathcal{F} 1991 ; 65: 179-83$.

8 Franciosa JA, Leddy CL, Wilen M, Schwartz DE. Relation between hemodynamic and ventilatory responses in determining exercise capacity in severe congestive heart failure. Am $\mathcal{F}$ Cardiol 1984;53:127-34

9 Rubin SA, Brown HV, Swan HJC. Arterial oxygenation and arterial oxygen transport in chronic myocardial failure at rest, during exercise and after hydralazine treatment. Circulation 1982;66:143-8.

10 Fink LI, Wilson JR, Ferraro N. Exercise ventilation and pulmonary artery wedge pressure in chronic stable congestive heart failure. Am $\mathscr{f}$ Cardiol 1986;57:249-53. 
11 Weber KT, Kinasewitz GT, West JS, Janicki JS, Reichek N, Fishman AP. Long term vasodilator therapy with trimazosin in chronic cardiac failure. $N$ Engl $f$ Med trimazosin in chromit

12 Davies NJH, Dennison DM. The measurement of metabolic gas exchange and minute volume by mass spectrometry alone. Respir Physiol 1979;36:261-7.

13 Jones NL, Campbell EJ. Clinical exercise testing. 2nd ed. Philadelphia: WB Saunders, 1982:25.

14 Wilson JR, Martin JL, Schwartz D, Ferraro N. Exercise tolerance in patients with chronic heart failure: role of impaired nutritive flow to skeletal muscle. Circulation 1984;69:1079-87.

15 Wilson JR, Martin JL, Ferraro N, Weber KT. Effect of hydralazine on perfusion and metabolism in the leg during upright bicycle exercise in patients with heart failure: ing upright bicycle exercise in patients with heart failure: role of impaired nutritive

16 Drexler H. Skeletal muscle failure in heart failure Circulation 1992;85:1621-3.

17 Jones NL, Campbell EJ. Clinical exercise testing. 2nd edn. Philadelphia: WB Saunders, 1982:34.

18 Tani $M$, Fujiki A, Asanoi $H$, Yoshida $S$, Tsuji $H$ Mizumaki $\mathrm{K}$, et al. Effects of chronotropic responsive cardiac pacing on ventilatory response to exercise in cardiac pacing on ventiatory response to exercise in patients

19 Rubanyi GM, Romero JC, Vanhoutte PM. Flow-induced release of endothelium-derived relaxing factor. $A m \mathcal{F}$ Physiol 1986;250:H1145-9.
20 Pohl U, Busse R, Kuon N, Bassenge E. Pulsatile perfusion stimulates the release of endothelial autocoids. $f$ Appl Cardiol 1986;I:215-35.

21 Griffith TM, Edwards DH, Davies RLl, Harrison TJ, Evans KT. EDRF coordinates the behaviour of vascular resistance vessels. Nature 1987;329:442-4.

22 Katz SD, Biasucci L, Sabba C, Strom JA, Jondeau G, Galvao $M$, et al. Impaired endothelium-mediated vasodilatation in the peripheral vasculature of patients with congestive heart failure. $\mathcal{F}$ Am Coll Cardiol 1992; 19:918-25.

23 Kubo SH, Rector TS, Bank AJ, Williams RE, Heifetz SM. Endothelium-dependent vasodilation is attenuated in patients with heart failure. Circulation 1991;84: in patien.

24 Katz SD, Shwartz M, Yuen J, Le Jemtel TH. Impaired acetylcholine-mediated vasodilation in patients with congestive heart failure. Circulation 1993;88:55-61.

25 Shwartz M, Katz SD, Demopolous L, Hirsch H, Yuen J, Jondeau G, et al. Enhancement of endothelium dependant vasodilation by low dose nitroglycerine in patients with congestive heart failure. Circulation 1994;89: 1609-14.

26 Ontkean M, Gay R, Greenberg B. Diminished endothelium-derived relaxing factor activity in an experimental model of chronic heart failure. Circ Res 1991;69: 1088-96.

27 Drexler H, Hayoz D, Munzel T, Just H, Zelis R, Brunner HR. Endothelial function in congestive heart failure. $\mathrm{Am}$ Heart $\mathcal{f} 1993 ; 126: 761-4$. 